\title{
A multi-trajectory analysis of commonly co-occurring mental health issues across childhood and adolescence
}

\author{
Aja L. Murray ${ }^{1} \cdot$ Manuel Eisner $^{2,3} \cdot$ Daniel Nagin $^{4} \cdot$ Denis Ribeaud $^{3}$
}

Received: 3 June 2020 / Accepted: 28 October 2020 / Published online: 16 November 2020

(c) The Author(s) 2020

\begin{abstract}
Developmental trajectories of mental health issues can often be usefully summarised in a small number of clinically meaningful subtypes. Given the high levels of heterotypic and homotypic comorbidity in child and adolescent mental health symptoms, we explored whether it was possible to identify clinically meaningful developmental subtypes of multiple commonly co-occurring mental health issues. We evaluated the combined developmental trajectories of the most common and commonly co-occurring child and adolescent mental health issues: attention-deficit/hyperactivity disorder (ADHD), internalising, and externalising symptoms in a normative sample of youth with data $(n=1620)$ at ages $7,8,9,10,11,12,13$ and 15 using group-based multi-trajectory modelling. Multinomial logistic regression was used to evaluate predictors of group membership. Our optimal model included six trajectory groups, labelled 'unaffected', 'normative maturing', 'internalising', 'multimorbid late onset', 'multimorbid remitting', and 'multimorbid with remitting externalising'. Examining covariates of group membership suggested that males and bully victims tend to have complex mental health profiles; academic achievement and smoking during pregnancy have general associations with mental health irrespective of symptom developmental trajectories or combination; and maternal post-natal depression is primarily related to symptoms that are already in evidence by the beginning of the school years. Results suggest that developmental trajectories of commonly co-occurring mental health issues can be usefully summarised in terms of a small number of developmental subtypes. These subtypes more often than not involve multiple co-occurring mental health issues. Their association with mental health covariates depends on the combination and developmental timing of symptoms in ways that suggest they can be clinically informative.
\end{abstract}

Keywords Comorbidity $\cdot$ Developmental trajectories $\cdot$ Group-based trajectory modelling $\cdot$ Attention-deficit/hyperactivity disorder $\cdot$ Internalising problems $\cdot$ Externalising problems

\section{Introduction}

There is considerable variation across individuals in mental health symptom developmental trajectories. Often this can be usefully summarised in terms of just a small number of trajectory classes that can provide a clinically useful basis

Aja L. Murray

Aja.Murray@ed.ac.uk

1 Department of Psychology, University of Edinburgh, 7 George Square, Edinburgh EH8 9JZ, UK

2 Institute of Criminology, University of Cambridge, Cambridge, UK

3 Jacobs Center for Productive Youth Development, University of Zurich, Zurich, Switzerland

4 Carnegie Mellon University, Pittsburgh, PA, USA for subtyping. Early work, for example, delineated two major developmental trajectories of externalising problems: lifecourse persistent and adolescent limited [23], incorporated into diagnostic criteria for conduct disorder as a late versus early onset specifier [5]. Analyses of trajectory groups have been similarly informative in other domains, such as ADHD and internalising problems where there is now some discussion about adopting similar developmental specifiers [28, 36]. Mental health issues, however, show a strong tendency to cluster within individuals, even for supposedly distinct domains such as externalising and internalising problems (e.g., see Beauchaine and Cicchetti [7] for an overview). As such, to illuminate the development of mental health issues and their multimorbidity, it is essential to consider the codevelopment of symptoms across multiple domains when modelling potential developmental subtypes. 
Few studies have evaluated trajectory classes of mental health issues across multiple domains simultaneously (see [14, Girard, Tremblay, Nagin, and Côté 2019; 34, 37] for exceptions); however, the few that have provide initial demonstrations of the value of the approach. A small number of studies have, for example, used a growth mixture parallel process model approach $[37,47]$ to identify trajectory classes jointly defined by externalising and internalising symptoms. Using age 3-11 data from the UK-based Millennium Cohort Study, for example, Patalay et al. [37] identified 5 trajectory groups in their optimal model. These were labelled 'low symptoms', 'moderate behavioural', 'moderate emotional', 'high emotional and moderate behavioural' and 'high behavioural and moderate emotional'. Wiggins et al. [47] used a similar technique using age 3-9 data from the US-based Fragile Families study. Their optimal model included three joint trajectories, labelled 'normative' (initially low and declining internalising problems with initially medium and declining externalising problems), 'severedecreasing' (initially medium but decreasing internalising problems with initially high but decreasing externalising problems), and 'severe' (initially medium and increasing internalising problems with initially high but slightly decreasing externalising problems).

An important gap in these studies relates to the co-development of externalising and internalising problems with other common symptoms in youth. ADHD symptoms are likely to be particularly relevant for understanding how and why externalising and internalising problems co-develop. ADHD is among the most common disorders in childhood, affecting around 5-7\% globally [39, Polanczyk et al. 2015; Thomas et al. 2015] and it is known to show significant comorbidity with both internalising problems [17] and externalising problems [3]. Moreover, developmental psychopathological theories suggest that, ADHD symptoms are causally antecedent to both internalising and externalising problems [8, 24; Murray et al. 2020], thus providing an important potential link between internalising and externalising trajectories,

However, describing developmental trajectory groups is primarily helpful if they map to clinically meaningful groups that, for example, differ in etiology, outcomes, or treatment responses. By extension, identifying the factors that differentiate trajectory groups can inform early identification of the symptom trajectories that a child is most likely to follow and can thus help inform early diagnosis and prediction of likely support needs and optimal treatments. However, there is currently very little information available on covariates of joint trajectory group membership, and where covariates have been examined, most fail to differentiate between groups affected by elevated symptoms but with different profiles in terms of predominant symptoms [14, Hinnant and El-Sheikh 2013, 37]. Patalay et al. [37], for example, examined predictors of the five joint emotional/behavioural problems trajectories that they identified in the Millennium Cohort Study. Candidate predictors included sex, ethnicity, income, parental education, parental occupation, lone family status, number of siblings, maternal and paternal psychological distress, parent relationship state, parent-child conflict and closeness, smoking household, maternal age at birth, unplanned pregnancy, birthweight, smoking during pregnancy, gross motor delays, relative age, child temperament dimensions; and early childhood physical health, cognitive ability, self-regulation and emotional dysregulation. However, only a small subset of predictors differentiated between children with more prominent emotional versus more prominent behavioural symptoms when overall levels of (emotional + behavioural) symptoms were similar. For example, only sex, ethnicity, maternal age at birth and infant apprehension predicted membership in the group where emotional symptoms were predominant at higher overall levels of symptoms. Similarly, only sex, ethnicity, having 2 siblings (but not 1 or 3), smoking during pregnancy, maternal psychological distress, parent-child conflict, and infant apprehension predicted membership in the groups where emotional symptoms were predominant at moderate overall levels of symptoms.

Given the lack of research to date on the joint developmental trajectories of ADHD, internalising and externalising problem symptoms, we examined joint developmental trajectories in these domains in a normative sample of youth measured at ages 7, 8, 9, 10,11,12,13, and 15 in the z-proso study. We also evaluated whether established covariates of these common mental health issues in youth differentiated individuals who were assigned to the trajectory classes that emerged. There are a very large number of covariates that have been previously linked to mental health issues in childhood and adolescence, many of which were available for our sample; however, for practical reasons of alpha inflation control we limited our analyses to just a subset of candidate covariates. We selected these predictors based on seeking to cover risk factors at different stages of development and based on prior evidence of representing promising candidates for differentiating trajectories dominated by symptoms in different domains. The inclusion of covariates relating to three different stages of development was based on prior evidence that mental health developmental subtypes may correspond to the presence of risk factors and outcomes at different stages of development [36]. We thus evaluated two perinatal risk factors: maternal smoking during pregnancy and maternal post-natal depression [35, 44]; two childhood covariates: child sensation-seeking and socioeconomic status (SES) at age 7 (previous research suggests that SES in childhood is more strongly linked to mental health issues than SES in adolescence; [40]) and two early adolescence covariates: bullying victimisation and academic achievement 
at age $11[4,22]$. Though difficult to identify covariatespecific associations because of mental health comorbidity and other confounding factors, past research has suggested that these predictors also show differential relations with ADHD, externalising problems, and internalising problems. Specifically, smoking during pregnancy may be particularly strongly related to ADHD and externalising problems [44]; maternal depression to internalising problems [14]; sensation-seeking to ADHD and externalising problems (e.g., [16, 19]); SES to ADHD and externalising problems [40]; bullying victimisation to internalising problems [4]; and academic achievement to ADHD and externalising problems [22, 40]. However, with only a few exceptions there has been little consideration of the relations between these covariates and combinations of mental health problems, especially taking their developmental trajectories into account. We hypothesised that smoking during pregnancy, sensation-seeking, SES, and academic achievement would differentiate any trajectory groups involving elevated ADHD and externalising problems from groups not affected by elevated symptoms in these domains, irrespective of whether these trajectories also involved internalising problems. On the other hand, we hypothesised that maternal post-natal depression and bullying victimisation would differentiate trajectories involving elevated internalising problems from those unaffected by symptoms in this domain, irrespective of whether these trajectories also involved elevated ADHD symptoms and externalising problems.

\section{Methods}

\section{Ethical considerations}

Ethical approval was obtained from the Ethics Committee of the Faculty of Arts and Social Sciences of the University of Zurich.

\section{Participants}

Participants were from the Zurich Project on Social Development from Childhood to Adulthood (z-proso) longitudinal cohort study. The current study used the teacher-reported data, which was available at waves ages $7,8,9,10,11,12,13$, and 15 , beginning in 2004. Participants were selected via a stratified random sample of schools in Zurich. First, all 90 public primary schools in the city of Zurich were blocked by size and school district, the latter to take account of area-based socioeconomic variation. Next, 14 groups of schools were created crossing size and SES and four schools randomly drawn from each. All fifty-six sampled schools took part as participation was made mandatory by the school authorities. Within these schools, all children entering first grade were invited to participate, giving a target sample of 1675 from 116 classes, of whom 1620 contributed data utilised in the current study.

At baseline, most participating children (90\%) were born between May 1997 and April 1998, October 1997 being the mean month of birth. Approximately half (51.9\%) were male. While almost $90 \%$ of the sample were born in Switzerland, only a minority $(42.6 \%)$ of their female primary caregivers and a similar proportion of their male primary caregivers were born in Switzerland. Other common primary caregiver nations of origin included Germany, Italy, Serbia and Montenegro, Yugoslavia, and Turkey. The mean International SocioEconomic Index of Occupational Status (ISEI) score [15] was 44.82 (approximately corresponding to the occupational prestige of a book-keeping clerk; $\mathrm{SD}=17.75$ ).

Considerable efforts were made to maximise recruitment and retention in the study. At baseline, for example, contact letters were written in the 10 languages most commonly spoken by parents, with fieldworkers who were native speakers of these languages assigned to recruit and interview parents. Incentives, translated support letters from schools, monetary incentives, and follow-up by phone were also employed to enhance participation. These measures helped achieve good response rates, with some data available for $97 \%$ of the children in the original target sample, allowing them to be included in the current analysis.

Non-response and attrition for this sample has been complex and non-monotonic due to the pattern of consent renewals at various phases and the fact that parents could decline to provide information on their child and yet still consent to teachers providing information on their child. This meant that some children have data only from a subset of informants (self-versus teacher versus parents) and/or at a subset of waves, including some cases of children who did not initially participate in the study due to a lack of parental consent but who joined the study at a later stage when consent was collected directly from participating children. The number of participants with teacher-reported mental health data (the variables used to define the trajectories in the current study) at each wave were for age 7: $n=1349$; age 8: $n=1344$; age 9: $n=1293$; age 10: $n=1269$; age 11: $n=1063$; age $12: n=976$; age 13: $n=1268$; and age 15: $n=1292$.

Analyses of non-response suggested that the participating sample differs little from those who did not participate [13]. The main difference is that children who did not participate at baseline were more likely to have a primary caregiver who did not speak German (the official language of the study location) as their first language.

\section{Procedure}

Self-reported questionnaire data (bullying victimisation at age 11) were collected as part of a broader questionnaire measuring psychosocial development and administered in 
German, the official local language, in paper and pencil format. Data were collected in groups of between 3 and 25 students in a classroom setting but during leisure time with no teacher present. Between 1 and 3 fieldworkers were present to lead the data collection sessions and provide assistance where needed. Behavioural data (sensation-seeking) were also collected from the children at age 7, the procedure for which is described in the Measures section.

Primary caregiver-reported questionnaire data (perinatal risk factors) were collected using computer assisted personal interviews (CAPI) in one of 10 languages, depending on the mother tongue of the respondent. Interviews were conducted in the home of the primary caregiver by trained fieldworks. The data used in the current study were part of a broader questionnaire assessing child psychosocial development, developmental history, and family background.

Teacher-reported data (ADHD, internalising problems, externalising problems, and academic achievement data) were collected by mail and were part of a broader questionnaire measuring child psychosocial development. The questionnaires were administered in German in paper and pencil format.

\section{Measures}

Externalising, internalising, and ADHD symptoms were measured using an adapted teacher report version of the Social Behavior Questionnaire [45]. Within the externalising domain, 6 items measured oppositional defiant disorder and conduct disorder and 9 measured aggression. Within the internalising domain, 3 items measured anxiety and 4 measured depression. Within the ADHD domain, 4 items measured inattention and 4 measured hyperactivity/impulsivity. Inattention and hyperactivity/impulsivity were combined into a single composite because of their high correlation and similarity of developmental trajectories in z-proso [26, 28]. Composite scores were created for each SBQ subscale by item score summation. All items were identical across the measurement waves included in the current study. The reliability and validity of the SBQ scores have been supported in previous research $[28,29,45]$. In the current study the omega reliability [21] values were all $>0.90$. Teacher reports were used for the mental health data because they covered the entire range of mandatory schooling (ages 7-15) in the study location in the same format. Self-reports were available for a similar age range but switched from computerised to questionnaire format in adolescence and were therefore not comparable across childhood and adolescence. They were also less comprehensive than the teacher-reports. Parent-reports were available only up until late childhood and were not available for adolescence.
Maternal smoking during pregnancy was measured using an item: 'Did you smoke cigarettes during your pregnancy?' administered to primary caregivers as part of the baseline assessment. Response options offered were yes, no, not applicable, don't know/can't remember and no answer. In some cases $(n=75)$, it was not the mother who responded to the questionnaire. In these cases, the respondent (e.g., the father) was asked whether the mother had smoked during the pregnancy.

Maternal post-natal depression was measured using an item: 'After < child name > 's birth did you suffer from post-natal depression?'. As with maternal smoking during pregnancy, in cases where the mother was not the informant $(n=75)$, the informant was asked whether the mother experienced post-natal depression.

Sensation-seeking at age 7 was measured using an adapted 9-item version of the travel game developed by Alsaker and Gutzwiller-Helfenfinger [2], comprehensively described in Murray, Eisner, Obsuth et al. [28]. In brief, scores were derived from a behavioural game 'The Travel Game' in which children could choose different options that were more or less 'sensation-seeking'. Assessments were carried out individually by specially trained investigators and took place during normal school time. Omega reliability for the scale in the current sample was 0.80. Composite scores were derived by summation of the individual item scores.

Bullying victimisation at age 11 was measured using the self-reported 4-item Zurich Brief Bullying Scales (ZBBS; [25]). The ZBBS as was administered at the age 11 wave of $\mathrm{z}$-proso includes four victimisation items referring to being purposely ignored or excluded; laughed at, mocked or insulted; hit, bitten, kicked or having hair pulled; and having possessions stolen, broken or hidden. The items were self-reported and measured frequency of victimization on a six-point scale from never to (almost) every day. Omega reliability for the ZBBS victimization items in the current sample was 0.72 . Composite scores were derived by summation of the individual item scores.

Academic achievement at age 11 was measured as the average of maths and language competence scores. These scores were provided by teachers based who rated the child's competence in each domain on a five-point scale from much worse to much better [than the average student]. The correlation between maths and language competence scores was $r=0.72(p<0.001)$.

\section{Statistical procedure}

To explore whether we could parse the heterogeneity in joint ADHD, externalising, and internalising trajectories into meaningful subgroups, we used group based multitrajectory analysis, comprehensively described in [32]. In 
brief, GBTM is a form of finite mixture modelling for longitudinal data and group based multi-trajectory modelling provides a generalisation of the technique to situations where trajectory group membership may be defined by multiple indicators. Unlike growth mixture modelling, it does not permit within-class variation, reflecting the fact that the classes are conceptualised as a convenient summary of a continuous distribution rather than representing true subtypes. We fit models with between 1 and 6 classes and compared the Akaike's information criterion (AIC), Bayesian information criterion (BIC) and sample size adjusted BIC (saBIC) associated with each for the purposes of model selection. We did not go beyond 6 classes in order to preserve parsimony given the sample size available. Models with linear growth only and models with both linear and quadratic growth were fit. Given how AIC, BIC and saBIC values are calculated for these models, larger (more positive) values indicate better fitting models in this context [30]. These models were fit using Stata version 15.

We then examined the association between covariates of common mental health issues and class membership based on our chosen 'best fitting' model. Class membership was regressed on the covariates in a series of multinomial logistic regressions, in a single step. In contrast to other approaches to modelling heterogeneity in longitudinal trajectories (see e.g., Asparouhov and Muthén 2014), it has been shown the inclusion of predictors is unlikely to affect the formation of groups in GBTM, therefore, multistep methods are not necessary [41]. To help ensure this we used the parameter estimates from the models without any predictors as the starting values for the trajectory parameters in the model with the predictors and subsequently checked that the model-predicted values did not differ substantively across the models with and without predictors. Missing data were dealt with using multivariate imputation with chained equations, using the mice package in $\mathrm{R}$ [9]. The imputation model included all of the previously described covariates, variables previously identified as predictors of attrition in this sample [13], ADHD, externalising, and internalising, and several putative outcome variables discussed in a related paper (delinquency, social exclusion, optimism, intimate partner violence perpetration and victimisation; [25]). We used three imputed datasets, with results pooled using Rubin's rules [43]. We used an imputation approach rather than a weighting approach to deal with non-random attrition because this allowed us to include more datapoints, especially given that attrition was non-monotonic and involved item- as well as unit non-response (e.g., Seaman et al. 2012). This method yields unbiased parameter estimates provided that data are missing at random (MAR; [42]).

\section{Results}

Descriptive statistics are provided in Table 1. Before interpreting the pooled results, models from the three imputations were inspected and are presented separately for each imputation in order to ensure that the same GBTM model emerged across the imputations. Fit statistics across the three imputed datasets are provided in Table 2. Fit statistics mainly favoured the 6-group model with quadratic growth, though BIC (which has the larger parsimony penalty) sometimes favoured the 6-group model with linear growth only. On balance, we preferred the model with both linear and quadratic growth because it allowed us to avoid the possibility of mis-specifying non-linear growth as linear. Figure 1 summarises this model, based on the parameter estimates from the first imputation (parameter estimates from all imputations were highly similar and are provided in Tables 3,4,5 and plotted in Figs. 2 and 3).

Based on the first imputation, Group 1 (32.5\% of the sample) was characterised by low levels of all three mental health issues and was, therefore, labelled 'unaffected'. Group 2 (10.6\%) was characterised by low levels of ADHD and externalising problems but elevated internalising problems and was, therefore, labelled 'internalising'. In the third imputed dataset, this group also showed some ADHD symptom elevations, possibly reflecting the negative impact of internalising symptoms on concentration. This was the only substantive difference in the groups across the three imputations. Group 3 (13.5\%) was characterised by increasing levels of ADHD, externalising problems and internalising problems over the course of development and was, therefore, labelled 'multimorbid late onset'. Group $4(27.9 \%)$ was characterised by initially slightly elevated levels of ADHD, externalising problems and internalising problems that declined over the course of development. As many children can show initial mild symptoms that they 'grow out of' (especially hyperactive and externalising problems), group 4 was labelled 'normative maturing'. Group $5(12.0 \%)$ was characterised by initially elevated ADHD, internalising and externalising symptoms that declined towards later adolescence. This group was, therefore, labelled 'multimorbid remitting'. Finally, group $6(3.4 \%)$ was characterised by stably elevated levels of ADHD and internalising symptoms but declining levels of externalising problems. Group 6 was, therefore, labelled 'multimorbid with remitting externalising.'

\section{Covariates of trajectory classes}

Results of the multinomial logistic regressions predicting class membership are provided in Table 6 . Coefficients represent the differences between each class and the 
Table 1 Descriptive statistics

\begin{tabular}{|c|c|c|c|}
\hline & $\mathrm{n}$ & Mean & $\mathrm{SD}$ \\
\hline ADHD age 7 & 1312 & 15.66 & 7.04 \\
\hline ADHD age 8 & 1305 & 14.59 & 6.91 \\
\hline ADHD age 9 & 1283 & 14.34 & 6.69 \\
\hline ADHD age 10 & 1252 & 14.59 & 6.96 \\
\hline ADHD age 11 & 1053 & 14.31 & 6.97 \\
\hline ADHD age 12 & 970 & 13.78 & 6.62 \\
\hline ADHD age 13 & 1242 & 14.08 & 6.69 \\
\hline ADHD age 15 & 1276 & 13.92 & 6.56 \\
\hline Internalising age 7 & 1302 & 13.03 & 5.29 \\
\hline Internalising age 8 & 1303 & 12.43 & 5.08 \\
\hline Internalising age 9 & 1281 & 12.90 & 5.19 \\
\hline Internalising age 10 & 1240 & 13.24 & 5.15 \\
\hline Internalising age 11 & 1034 & 13.31 & 5.32 \\
\hline Internalising age 12 & 967 & 13.19 & 5.39 \\
\hline Internalising age 13 & 1232 & 13.13 & 5.33 \\
\hline Internalising age 15 & 1265 & 13.09 & 5.27 \\
\hline Externalising age 7 & 1263 & 25.08 & 9.62 \\
\hline Externalising age 8 & 1266 & 24.67 & 9.08 \\
\hline Externalising age 9 & 1240 & 25.20 & 9.45 \\
\hline Externalising age 10 & 1213 & 24.28 & 9.48 \\
\hline Externalising age 11 & 1039 & 23.75 & 8.78 \\
\hline Externalising age 12 & 953 & 23.97 & 9.35 \\
\hline Externalising age 13 & 1207 & 22.28 & 8.05 \\
\hline Externalising age 15 & 1221 & 22.29 & 7.79 \\
\hline Gender & Male $=870 ;$ female $=805$ & & \\
\hline Smoking during pregnancy & Exposed $=197 ;$ not exposed $=1023$ & & \\
\hline Maternal post-natal depression & Exposed $=160 ;$ not exposed $=1058$ & & \\
\hline Sensation seeking age 7 & 1355 & 13.95 & 1.35 \\
\hline Bully victimisation age 11 & 1140 & 7.11 & 3.16 \\
\hline Academic achievement age 11 & 1061 & 6.56 & 2.37 \\
\hline
\end{tabular}

reference 'unaffected' class. Males were over-represented in the multimorbid late onset, multimorbid remitting, and multimorbid with remitting externalising groups but there were no gender differences in the internalising nor normative maturing groups. In terms of perinatal factors, smoking during pregnancy predicted increased risk of membership in all groups relative to the unaffected group, while maternal post-natal depression was associated with an increased risk of membership in the internalising, normative maturing, and multimorbid remitting groups only. In terms of covariates in childhood and adolescence, sensation-seeking was unrelated to membership in any of the groups; bullying victimisation predicted an increased risk of membership in all but the internalising group; and low academic achievement predicted an increased risk of membership in all groups relative to the unaffected group.

\section{Discussion}

In this study, we aimed to distil the combined developmental trajectories of multiple commonly co-occurring mental health issues (ADHD, internalising problems and externalising problems) into a small number of clinically meaningful trajectory groups that could be distinguished on the basis of established correlates of child and adolescent psychopathology. Using group-based trajectory modelling, we identified six trajectory groups. Two covariates: smoking during pregnancy and low academic achievement were related to membership in all groups relative to the unaffected group while others exhibited more specific associations with trajectory groups.

Two groups characterised by relatively low symptom levels and labelled 'unaffected' and 'normative maturing' respectively accounted for the majority of the sample. The former was characterised by consistently low levels of psychopathology across development while the latter showed 


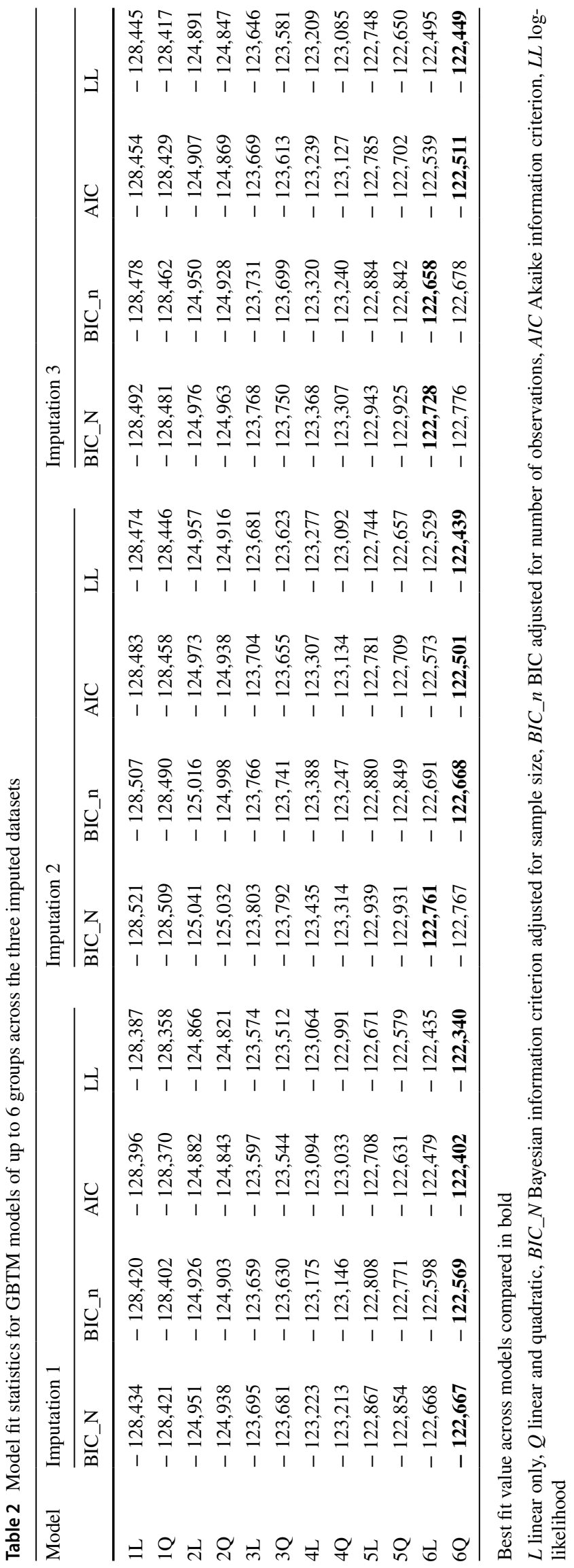




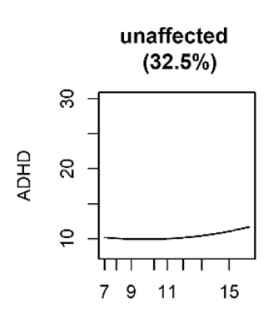

age

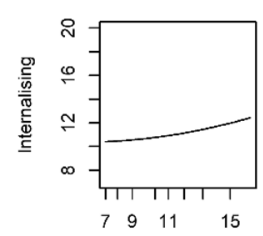

age

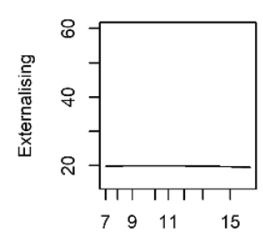

age

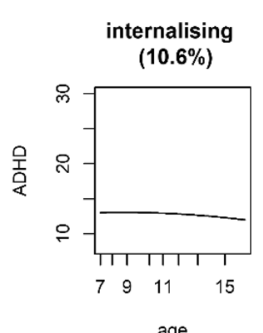

age

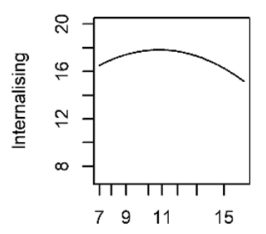

age

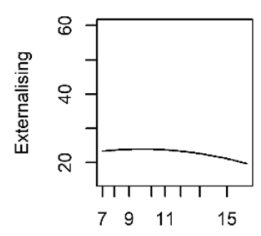

age

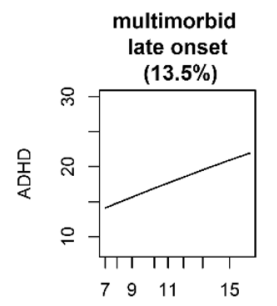

age

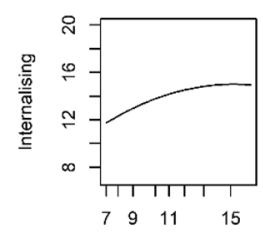

age

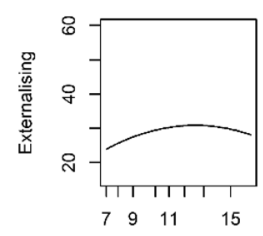

age
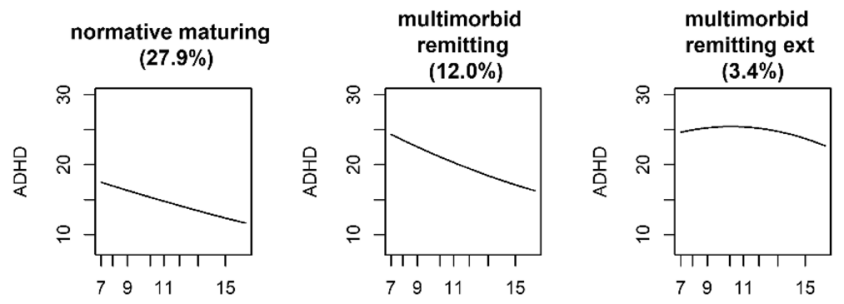

age
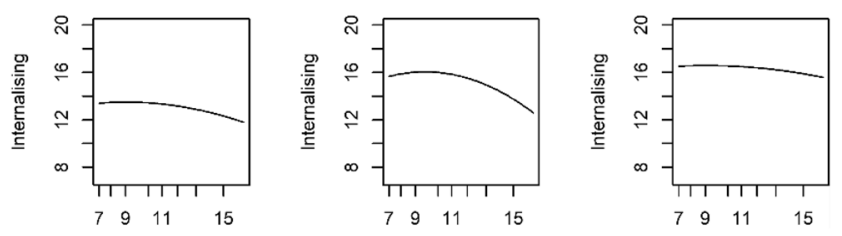

age

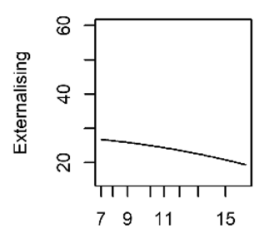

age

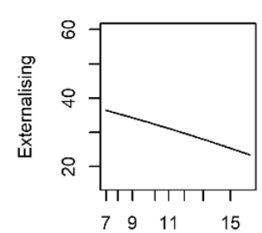

age

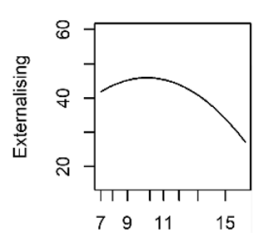

age

Fig. 1 Trajectories for the 'best-fitting' (6-group) model based on imputation 1

early minor elevations only. The normative maturing group was assumed to reflect the fact that many symptoms that appear early in life, especially hyperactivity and behavioural problems disappear naturally as children's emotional and behavioural regulation abilities improve with maturation (e.g., Lahey et al. [18]).

The remaining groups were characterised by some form of elevation of psychopathology. One group (approximately $10 \%$ of the sample, labelled 'internalising') was characterised by elevations primarily in internalising problems. All other groups showed elevations in multiple areas, supporting the idea that most individuals with mental health issues experience symptoms in more than one domain [33]. The developmental coupling of symptoms is not surprising in the context of contemporary models of ADHD-internalising-externalising comorbidity. These variously argue that ADHD symptoms and externalising problems can lead to anxiety and depression via associated psychosocial difficulties; that anxiety and depression may interfere with attention, exacerbating ADHD symptoms; and that ADHD symptoms may lead to externalising problems via an escalating cascade of behaviour problems [8, 17, Murray et al. 2020; 46; Wolff and Ollendick 2006].

One of the multimorbid groups (approximately 14\% of the sample; labelled 'multimorbid late onset') was characterised by initially low but increasing in all three symptom areas across development. Another group (approximately $12 \%$ of the sample; labelled 'multimorbid remitting') was characterised by initially high levels of all three symptom areas that decreased over the course of development leaving some residual symptom elevation at age 15 . The final group (approximately $3 \%$ of the sample; labelled 'multimorbid with remitting externalising') was characterised by consistently elevated ADHD and internalising symptoms but late-declining externalising problems. The presence of this group implies a need to avoid assuming that the resolution of behavioural issues (which are often the symptoms most easily detected) implies a resolution of all symptoms. Some with remitting behavioural symptom may retain high levels of internal distress and ADHD symptoms that could interfere with their functioning, as suggested by the fact that this group had poorer academic achievement and higher levels of bullying victimisation compared to the unaffected group.

Further insights into the nature of the groups were provided by comparisons of the 'unaffected' group with the remaining five groups. These comparisons underlined the importance of a developmental perspective that takes into account the joint trajectories of commonly co-occurring mental health issues. For example, analyses suggested that males were more likely to have complex profiles involving both behavioural and emotional difficulties. They were over-represented in the multimorbid late onset, multimorbid 
Table 3 Trajectory parameter estimates from 'best fitting' (6-class with linear and quadratic growth) model in first imputed dataset

\begin{tabular}{|c|c|c|c|c|c|}
\hline Group & Parameter & Estimate & SE & $T$ & $P$ \\
\hline \multicolumn{6}{|l|}{ ADHD } \\
\hline \multirow[t]{3}{*}{1} & Intercept & 13.757 & 1.443 & 9.536 & $<0.001$ \\
\hline & Linear & -0.760 & 0.262 & -2.901 & 0.004 \\
\hline & Quadratic & 0.038 & 0.011 & 3.295 & 0.001 \\
\hline \multirow[t]{3}{*}{2} & Intercept & 11.766 & 3.059 & 3.847 & $<0.001$ \\
\hline & Linear & 0.286 & 0.559 & 0.512 & 0.609 \\
\hline & Quadratic & -0.016 & 0.024 & -0.661 & 0.508 \\
\hline \multirow[t]{3}{*}{3} & Intercept & 7.050 & 2.595 & 2.716 & 0.007 \\
\hline & Linear & 1.004 & 0.472 & 2.129 & 0.033 \\
\hline & Quadratic & -0.008 & 0.021 & -0.365 & 0.715 \\
\hline \multirow[t]{3}{*}{4} & Intercept & 23.033 & 2.086 & 11.042 & $<0.001$ \\
\hline & Linear & -0.800 & 0.361 & -2.213 & 0.027 \\
\hline & Quadratic & 0.008 & 0.015 & 0.502 & 0.615 \\
\hline \multirow[t]{3}{*}{5} & Intercept & 33.567 & 2.619 & 12.816 & $<0.001$ \\
\hline & Linear & -1.410 & 0.476 & -2.964 & 0.003 \\
\hline & Quadratic & 0.023 & 0.020 & 1.133 & 0.257 \\
\hline \multirow[t]{3}{*}{6} & Intercept & 17.168 & 4.565 & 3.761 & $<0.001$ \\
\hline & Linear & 1.533 & 0.826 & 1.856 & 0.064 \\
\hline & Quadratic & -0.071 & 0.036 & -1.981 & 0.048 \\
\hline \multicolumn{6}{|c|}{ Internalising } \\
\hline \multirow[t]{3}{*}{1} & Intercept & 10.874 & 1.398 & 7.779 & $<0.001$ \\
\hline & Linear & -0.183 & 0.253 & -0.724 & 0.469 \\
\hline & Quadratic & 0.016 & 0.011 & 1.474 & 0.141 \\
\hline \multirow[t]{3}{*}{2} & Intercept & 6.913 & 3.444 & 2.008 & 0.045 \\
\hline & Linear & 1.916 & 0.597 & 3.208 & 0.001 \\
\hline & Quadratic & -0.084 & 0.025 & -3.331 & 0.001 \\
\hline \multirow[t]{3}{*}{3} & Intercept & 3.458 & 2.421 & 1.429 & 0.153 \\
\hline & Linear & 1.456 & 0.440 & 3.311 & 0.001 \\
\hline & Quadratic & -0.046 & 0.019 & -2.400 & 0.016 \\
\hline \multirow[t]{3}{*}{4} & Intercept & 11.094 & 1.801 & 6.160 & $<0.001$ \\
\hline & Linear & 0.519 & 0.325 & 1.594 & 0.111 \\
\hline & Quadratic & -0.028 & 0.014 & -1.989 & 0.047 \\
\hline \multirow[t]{3}{*}{5} & Intercept & 9.528 & 2.370 & 4.020 & $<0.001$ \\
\hline & Linear & 1.325 & 0.426 & 3.114 & 0.002 \\
\hline & Quadratic & -0.067 & 0.018 & -3.667 & $<0.001$ \\
\hline \multirow[t]{3}{*}{6} & Intercept & 15.184 & 4.395 & 3.455 & 0.001 \\
\hline & Linear & 0.301 & 0.794 & 0.379 & 0.705 \\
\hline & Quadratic & -0.016 & 0.034 & -0.472 & 0.637 \\
\hline \multicolumn{6}{|c|}{ Externalising } \\
\hline \multirow[t]{3}{*}{1} & Intercept & 18.695 & 2.036 & 9.181 & $<0.001$ \\
\hline & Linear & 0.235 & 0.371 & 0.634 & 0.526 \\
\hline & Quadratic & -0.011 & 0.016 & -0.681 & 0.496 \\
\hline \multirow[t]{3}{*}{2} & Intercept & 15.101 & 4.288 & 3.522 & $<0.001$ \\
\hline & Linear & 1.759 & 0.790 & 2.226 & 0.026 \\
\hline & Quadratic & -0.088 & 0.034 & -2.538 & 0.011 \\
\hline \multirow[t]{3}{*}{3} & Intercept & -4.695 & 3.785 & -1.240 & 0.215 \\
\hline & Linear & 5.340 & 0.694 & 7.697 & $<0.001$ \\
\hline & Quadratic & -0.200 & 0.030 & -6.605 & $<0.001$ \\
\hline
\end{tabular}

Table 3 (continued)

\begin{tabular}{llrlrr}
\hline Group & Parameter & Estimate & \multicolumn{1}{l}{ SE } & \multicolumn{1}{l}{$T$} \\
\hline 4 & Intercept & 27.843 & 2.927 & 9.512 & $<0.001$ \\
& Linear & 0.124 & 0.522 & 0.238 & 0.812 \\
& Quadratic & -0.037 & 0.022 & -1.638 & 0.102 \\
5 & Intercept & 44.455 & 4.030 & 11.031 & $<0.001$ \\
& Linear & -0.946 & 0.727 & -1.302 & 0.193 \\
& Quadratic & -0.017 & 0.031 & -0.559 & 0.577 \\
6 & Intercept & -2.751 & 6.445 & -0.427 & 0.670 \\
& Linear & 9.286 & 1.161 & 8.001 & $<0.001$ \\
& Quadratic & -0.443 & 0.050 & -8.809 & $<0.001$ \\
\hline
\end{tabular}

Group $1=$ unaffected $(n=527 ; 32.5 \%$ of sample); group $2=$ internalising $(n=172 ; 10.6 \%)$; group $3=$ multimorbid late onset $(n=219$; $13.5 \%)$; group $4=$ normative maturing $(n=452 ; 27.8 \%)$; group $5=$ multimorbid remitting $(n=195 ; 21 \%) \mathrm{g}$; group $6=$ multimorbid externalising remitting $(n=55 ; 3.4 \%)$

remitting, and multimorbid with remitting externalising groups, but not the 'pure' internalising group. Previous discussions have tended to focus on sex differences in emotional versus behavioural symptoms [20] and little considered their combination. However, our results suggest that males who present with behavioural problems and ADHD are likely to be experiencing co-occurring internalising problems, underlining the importance of the inclusion of these symptoms in assessments even when they are not the reason for referral.

Similarly, we found that bullying victimisation was related to groups with mixed emotional-behavioural problem profiles but not to the group with the pure internalising profile. Thus, while internalising has been associated with bullying victimisation [4], our analyses suggest that this risk could be particularly important in the context of co-occurring ADHD and behavioural problems. This is consistent with the idea that children and adolescents who have behavioural problems are liable to elicit negative reactions from their peers, leading to rejection and victimisation [11].

The importance of considering the developmental timing of symptoms was highlighted by our finding that maternal post-natal depression was associated with an increased risk of membership in groups which had early emerging symptom elevations (internalising, normative maturing, multimorbid remitting) but not the group that showed lateemerging symptoms (multimorbid late onset). Our analyses thus suggest that early exposure to maternal post-natal depression does not necessarily result in lasting symptoms, for example, in the case of the normative maturing group; nor can it account for late onset symptoms, which may be more likely to have their origins in risk factors deriving from the late childhood and early adolescent period (e.g., Parkes et al. [36]). 
Table 4 Trajectory parameter estimates from 'best fitting' (6-class with linear and quadratic growth) model in second imputed dataset

\begin{tabular}{|c|c|c|c|c|c|}
\hline Group & Parameter & Estimate & SE & $t$ & $p$ \\
\hline \multicolumn{6}{|l|}{ ADHD } \\
\hline \multirow[t]{3}{*}{1} & Intercept & 14.420 & 1.445 & 9.978 & $<0.001$ \\
\hline & Linear & -0.864 & 0.261 & -3.303 & 0.001 \\
\hline & Quadratic & 0.041 & 0.011 & 3.626 & $<0.001$ \\
\hline \multirow[t]{3}{*}{2} & Intercept & 21.625 & 1.993 & 10.853 & $<0.001$ \\
\hline & Linear & -0.627 & 0.347 & -1.806 & 0.071 \\
\hline & Quadratic & 0.003 & 0.015 & 0.203 & 0.839 \\
\hline \multirow[t]{3}{*}{3} & Intercept & 10.746 & 2.759 & 3.895 & $<0.001$ \\
\hline & Linear & 0.285 & 0.506 & 0.563 & 0.574 \\
\hline & Quadratic & 0.027 & 0.022 & 1.199 & 0.230 \\
\hline \multirow[t]{3}{*}{4} & Intercept & 18.484 & 3.325 & 5.558 & $<0.001$ \\
\hline & Linear & -0.892 & 0.586 & -1.522 & 0.128 \\
\hline & Quadratic & 0.032 & 0.025 & 1.288 & 0.198 \\
\hline \multirow[t]{3}{*}{5} & Intercept & 37.024 & 2.551 & 14.516 & $<0.001$ \\
\hline & Linear & -2.136 & 0.467 & -4.574 & $<0.001$ \\
\hline & Quadratic & 0.054 & 0.020 & 2.670 & 0.008 \\
\hline \multirow[t]{3}{*}{6} & Intercept & 13.863 & 4.143 & 3.346 & 0.001 \\
\hline & Linear & 2.162 & 0.749 & 2.886 & 0.004 \\
\hline & Quadratic & -0.101 & 0.032 & -3.103 & 0.002 \\
\hline \multicolumn{6}{|c|}{ Internalising } \\
\hline \multirow[t]{3}{*}{1} & Intercept & 10.672 & 1.401 & 7.617 & $<0.001$ \\
\hline & Linear & -0.138 & 0.254 & -0.541 & 0.588 \\
\hline & Quadratic & 0.014 & 0.011 & 1.258 & 0.208 \\
\hline \multirow[t]{3}{*}{2} & Intercept & 6.424 & 1.929 & 3.330 & 0.001 \\
\hline & Linear & 1.384 & 0.338 & 4.098 & $<0.001$ \\
\hline & Quadratic & -0.064 & 0.014 & -4.508 & $<0.001$ \\
\hline \multirow[t]{3}{*}{3} & Intercept & 6.497 & 2.512 & 2.587 & 0.010 \\
\hline & Linear & 0.755 & 0.457 & 1.651 & 0.099 \\
\hline & Quadratic & -0.011 & 0.020 & -0.559 & 0.576 \\
\hline \multirow[t]{3}{*}{4} & Intercept & 15.956 & 4.221 & 3.780 & $<0.001$ \\
\hline & Linear & 0.251 & 0.723 & 0.347 & 0.728 \\
\hline & Quadratic & -0.009 & 0.030 & -0.298 & 0.766 \\
\hline \multirow[t]{3}{*}{5} & Intercept & 12.831 & 2.357 & 5.445 & $<0.001$ \\
\hline & Linear & 0.719 & 0.423 & 1.702 & 0.089 \\
\hline & Quadratic & -0.042 & 0.018 & -2.282 & 0.023 \\
\hline \multirow[t]{3}{*}{6} & Intercept & 13.082 & 3.916 & 3.341 & 0.001 \\
\hline & Linear & 0.792 & 0.705 & 1.122 & 0.262 \\
\hline & Quadratic & -0.039 & 0.031 & -1.290 & .197 \\
\hline \multicolumn{6}{|c|}{ Externalising } \\
\hline \multirow[t]{3}{*}{1} & Intercept & 17.649 & 2.051 & 8.606 & $<0.001$ \\
\hline & Linear & 0.451 & 0.374 & 1.206 & 0.228 \\
\hline & Quadratic & -0.021 & 0.016 & -1.301 & 0.193 \\
\hline \multirow[t]{3}{*}{2} & Intercept & 21.164 & 2.697 & 7.847 & $<0.001$ \\
\hline & Linear & 1.267 & 0.477 & 2.655 & 0.008 \\
\hline & Quadratic & -0.083 & 0.020 & -4.077 & $<0.001$ \\
\hline \multirow[t]{3}{*}{3} & Intercept & 2.687 & 3.879 & 0.693 & 0.488 \\
\hline & Linear & 3.620 & 0.714 & 5.073 & $<0.001$ \\
\hline & Quadratic & -0.116 & 0.031 & -3.688 & $<0.001$ \\
\hline
\end{tabular}

Table 4 (continued)

\begin{tabular}{llrlrr}
\hline Group & Parameter & Estimate & \multicolumn{1}{l}{ SE } & \multicolumn{2}{l}{$p$} \\
\hline 4 & Intercept & 18.018 & 4.618 & 3.902 & $<0.001$ \\
& Linear & 1.110 & 0.838 & 1.325 & 0.185 \\
& Quadratic & -0.057 & 0.036 & -1.573 & 0.116 \\
5 & Intercept & 50.683 & 3.982 & 12.728 & $<0.001$ \\
& Linear & -2.100 & 0.717 & -2.930 & 0.003 \\
& Quadratic & 0.029 & 0.031 & 0.947 & 0.344 \\
6 & Intercept & 0.050 & 6.156 & 0.008 & 0.994 \\
& Linear & 8.636 & 1.101 & 7.845 & $<0.001$ \\
& Quadratic & -0.420 & 0.047 & -8.917 & $<0.001$ \\
\hline
\end{tabular}

Group $1=$ unaffected $(n=528 ; 32.6 \%$ of sample); group $2=$ normative maturing $(n=464 ; 28.6 \%)$; group $3=$ multimorbid late onset $(n=210 ; 12.9 \%)$; group $4=$ internalising $(n=146 ; 9 \%)$; group $5=$ multimorbid remitting $(n=205 ; 12.7 \%)$; group $6=$ multimorbid with remitting externalising $(n=67 ; 4.2 \%)$

The fact that the groups identified were differentiable on the basis of some established risk factors for mental health issues suggests possible clinically meaningful distinctions between the groups. This merits further exploration as differences in clinically important factors such as etiology, sequelae, and treatment responses would make subtyping on the basis of trajectory groups useful for understanding the causes, support needs and optimal treatments for individuals presenting with different developmental patterns of (co-occurring) symptoms. At present, developmental trajectories are taken into account only in a small number of disorders, including conduct disorder, which has a specifier for age of onset (with an earlier age of onset indicating greater severity) $[5,26]$. To the extent that the trajectory groups in the current study are replicable and show to be distinguishable on the basis of clinically meaningful factors in future studies, it could be useful for clinical diagnostic criteria to incorporate specifiers for joint developmental trajectories of multiple symptoms to efficiently encode information regarding likely etiology, outcomes, and promising interventions.

Unfortunately, the present study is among only a few to model joint mental health trajectories, and the only (to the best of our knowledge) to model joint ADHD-externalisinginternalising trajectories across the school years age range. As such, there is currently little previous evidence on the extent to which the same trajectory groups emerge in different samples and can be differentiated on the basis of similar covariates to those studied here However, our results are consistent with previous studies in showing that individuals who belong to trajectory groups characterised by elevated externalising problems also tend to belong to trajectory groups characterised by elevated internalising problems (e.g., [34, 37]). Our study, however, differed in its findings from one of the few studies that explored trajectory groups 
Table 5 Trajectory parameter estimates from 'best fitting' (6-class with linear and quadratic growth) model in third imputed dataset

\begin{tabular}{|c|c|c|c|c|c|}
\hline Group & Parameter & Estimate & SE & $t$ & $p$ \\
\hline \multicolumn{6}{|l|}{ ADHD } \\
\hline \multirow[t]{3}{*}{1} & Intercept & 14.893 & 1.537 & 9.687 & $<0.001$ \\
\hline & Linear & -0.947 & 0.279 & -3.395 & 0.001 \\
\hline & Quadratic & 0.042 & 0.012 & 3.499 & 0.001 \\
\hline \multirow[t]{3}{*}{2} & Intercept & 15.954 & 3.155 & 5.057 & $<0.001$ \\
\hline & Linear & -0.614 & 0.584 & -1.051 & 0.293 \\
\hline & Quadratic & 0.048 & 0.027 & 1.822 & 0.069 \\
\hline \multirow[t]{3}{*}{3} & Intercept & 8.022 & 3.621 & 2.215 & 0.027 \\
\hline & Linear & 1.373 & 0.677 & 2.027 & 0.043 \\
\hline & Quadratic & -0.032 & 0.031 & -1.047 & 0.295 \\
\hline \multirow[t]{3}{*}{4} & Intercept & 15.954 & 1.964 & 8.121 & $<0.001$ \\
\hline & Linear & 0.068 & 0.348 & 0.195 & 0.846 \\
\hline & Quadratic & -0.023 & 0.015 & -1.544 & 0.123 \\
\hline \multirow[t]{3}{*}{5} & Intercept & 39.613 & 2.682 & 14.770 & $<0.001$ \\
\hline & Linear & -2.800 & 0.479 & -5.846 & $<0.001$ \\
\hline & Quadratic & 0.078 & 0.021 & 3.792 & $<0.001$ \\
\hline \multirow[t]{3}{*}{6} & Intercept & 18.881 & 3.378 & 5.589 & $<0.001$ \\
\hline & Linear & 1.370 & 0.610 & 2.246 & 0.025 \\
\hline & Quadratic & -0.076 & 0.026 & -2.884 & 0.004 \\
\hline \multicolumn{6}{|c|}{ Internalising } \\
\hline \multirow[t]{3}{*}{1} & Intercept & 10.744 & 1.511 & 7.110 & $<0.001$ \\
\hline & Linear & -0.144 & 0.273 & -0.528 & 0.597 \\
\hline & Quadratic & 0.013 & 0.012 & 1.086 & 0.277 \\
\hline \multirow[t]{3}{*}{2} & Intercept & 7.381 & 2.776 & 2.659 & 0.008 \\
\hline & Linear & 0.388 & 0.519 & 0.748 & 0.455 \\
\hline & Quadratic & 0.005 & 0.023 & 0.229 & 0.819 \\
\hline \multirow[t]{3}{*}{3} & Intercept & -1.431 & 3.529 & -0.405 & 0.685 \\
\hline & Linear & 2.528 & 0.654 & 3.863 & $<.001$ \\
\hline & Quadratic & -0.094 & 0.029 & -3.275 & 0.001 \\
\hline \multirow[t]{3}{*}{4} & Intercept & 8.936 & 1.860 & 4.803 & $<0.001$ \\
\hline & Linear & 1.298 & 0.326 & 3.984 & $<0.001$ \\
\hline & Quadratic & -0.064 & 0.014 & -4.570 & $<0.001$ \\
\hline \multirow[t]{3}{*}{5} & Intercept & 16.144 & 2.538 & 6.360 & $<0.001$ \\
\hline & Linear & 0.023 & 0.453 & 0.052 & 0.959 \\
\hline & Quadratic & -0.014 & 0.019 & -0.725 & 0.469 \\
\hline \multirow[t]{3}{*}{6} & Intercept & 10.241 & 3.434 & 2.982 & 0.003 \\
\hline & Linear & 1.263 & 0.617 & 2.046 & 0.041 \\
\hline & Quadratic & -0.061 & 0.027 & -2.295 & 0.022 \\
\hline \multicolumn{6}{|c|}{ Externalising } \\
\hline \multirow[t]{3}{*}{1} & Intercept & 17.472 & 2.137 & 8.174 & $<0.001$ \\
\hline & Linear & 0.499 & 0.388 & 1.285 & 0.199 \\
\hline & Quadratic & -0.026 & 0.017 & -1.549 & 0.121 \\
\hline \multirow[t]{3}{*}{2} & Intercept & 16.822 & 4.046 & 4.158 & $<0.001$ \\
\hline & Linear & 0.858 & 0.780 & 1.100 & 0.271 \\
\hline & Quadratic & -0.019 & 0.036 & -0.521 & 0.602 \\
\hline \multirow[t]{3}{*}{3} & Intercept & -10.430 & 5.568 & -1.873 & 0.061 \\
\hline & Linear & 6.722 & 1.063 & 6.326 & $<0.001$ \\
\hline & Quadratic & -0.261 & 0.048 & -5.445 & $<0.001$ \\
\hline
\end{tabular}

Table 5 (continued)

\begin{tabular}{llrlrr}
\hline Group & Parameter & Estimate & SE & \multicolumn{2}{l}{$t$} \\
\hline 4 & Intercept & 18.023 & 2.700 & 6.674 & $<0.001$ \\
& Linear & 1.661 & 0.481 & 3.456 & 0.001 \\
& Quadratic & -0.097 & 0.021 & -4.739 & $<0.001$ \\
5 & Intercept & 64.262 & 4.765 & 13.485 & $<0.001$ \\
& Linear & -4.791 & 0.817 & -5.867 & $<0.001$ \\
& Quadratic & 0.141 & 0.034 & 4.144 & $<0.001$ \\
6 & Intercept & 9.217 & 5.883 & 1.567 & 0.117 \\
& Linear & 6.718 & 1.054 & 6.375 & $<0.001$ \\
& Quadratic & -0.342 & 0.045 & -7.657 & $<0.001$ \\
\hline
\end{tabular}

Group $1=$ unaffected $(n=474 ; 29.3 \%$ of sample $)$; group $2=(n=251$; $15.5 \%)$; group $3=(n=135 ; 8.3 \%)$; group $4=(n=445 ; 27.4 \%)$; group $5=(n=215 ; 13.3 \%) ;$ group $6=(n=101 ; 6.2 \%)$

jointly characterised by internalising and externalising problems in showing evidence of a 'pure' internalising trajectory group. Specifically, Patalay et al. [37], who examined trajectory groups in a large representative sample, found no evidence of internalising problems occurring in the absence of externalising problems, as internalising symptoms were always accompanied by externalising problems at a higher or lower severity. Our study was, on the other hand, consistent with this previous study in finding that while a number of risk factors can differentiate those who are unaffected from those affected at some point in their development by some combination of symptoms, few are specific to particular trajectory groups [37].

Our group-based trajectory modelling approach provides complementary evidence to alternative approaches to modelling the development of co-occurring mental health issues. Previous work in this and other samples have, for example, examined the extent and longitudinal evolution of 'general comorbidity' sometimes also referred to as the ' $p$-factor', finding that there is considerable co-occurrence between symptoms in different domains across childhood and adolescent development $[10,24,25]$. Our finding here that most individuals who are affected by elevated symptoms fall into trajectory groups characterised by symptoms in multiple domains is thus consistent with this previous work but also helps to identify the specific developmental course that the co-occurring symptoms take. Future research connecting these alternative approaches e.g., through modelling the developmental trajectories of higher-order general factors of psychopathology may provide further insights into the developmental dynamics of co-occurring mental health issues.

\section{Limitations}

It is important to consider the limitations of the current study. First, the need to maintain adequate statistical power 

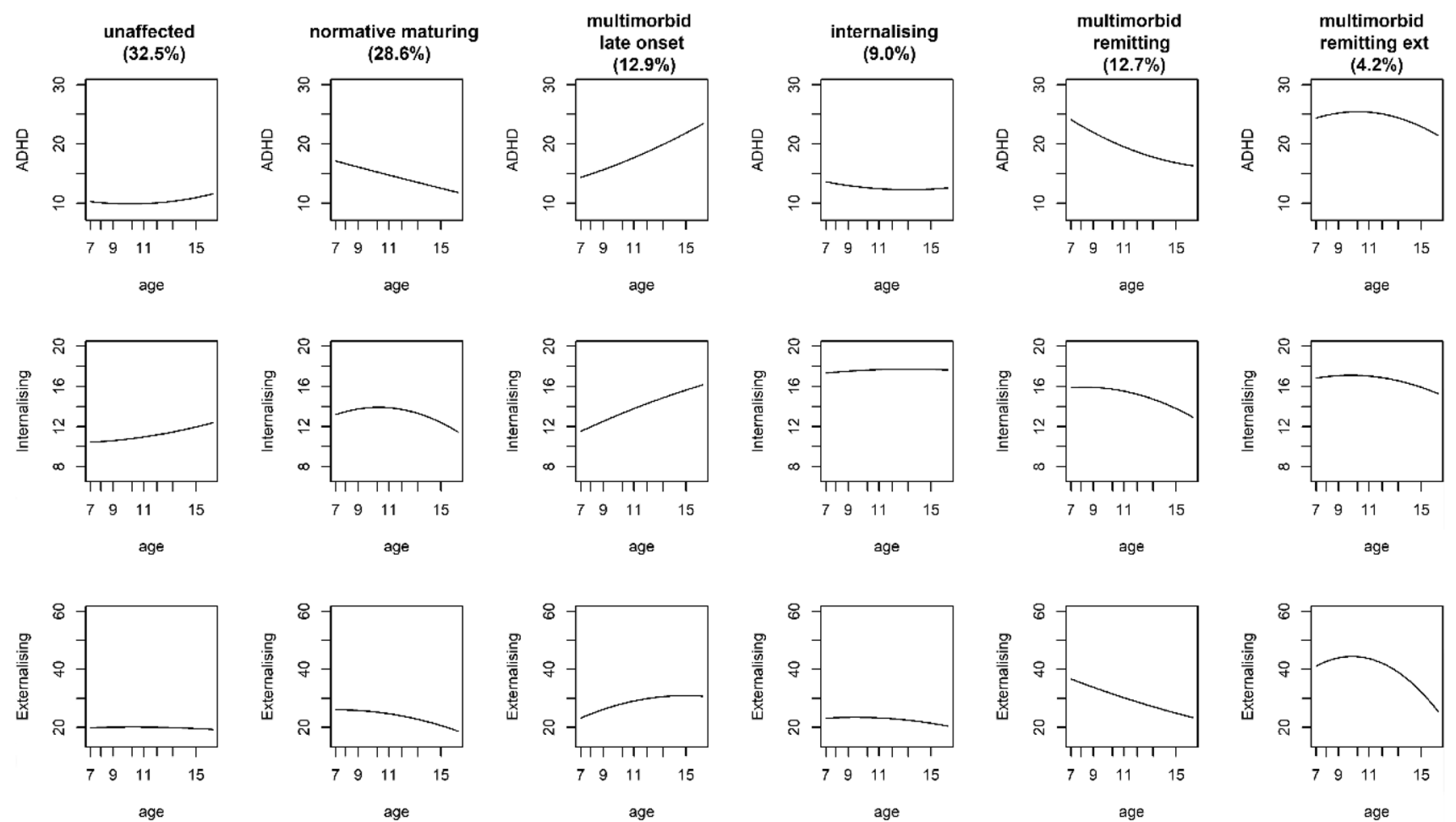

Fig. 2 Trajectories for the 'best-fitting' (6-group) model based on imputation 2
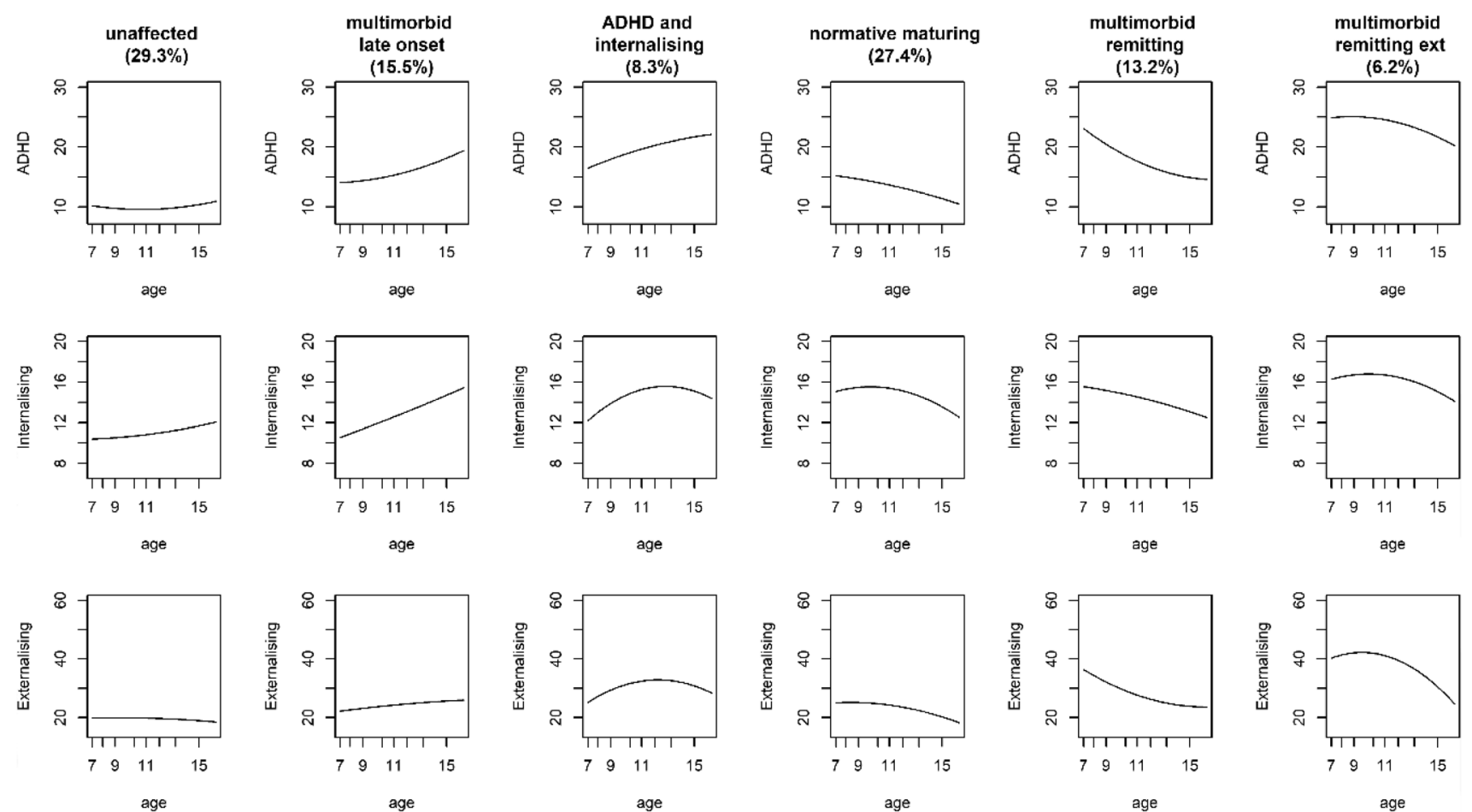

Fig. 3 Trajectories for the 'best-fitting' (6-group) model based on imputation 3 
Table 6 Multinomial logistic regression results

\begin{tabular}{|c|c|c|c|c|c|}
\hline Group & $\mathrm{B}$ & SE & Lower & Upper & OR \\
\hline \multicolumn{6}{|l|}{ Gender $(1=$ male, $2=$ female $)$} \\
\hline Internalising & -0.71 & 1.68 & -4.00 & 2.58 & 0.49 \\
\hline Multimorbid late onset & $-1.37 *$ & 0.56 & -2.47 & -0.27 & 0.25 \\
\hline Normative maturing & -0.63 & 0.38 & -1.38 & 0.12 & 0.53 \\
\hline Multimorbid remitting & $-1.39 *$ & 0.22 & -1.83 & -0.95 & 0.25 \\
\hline Multimorbid with remitting externalising & $-2.13 *$ & 0.36 & -2.84 & -1.42 & 0.12 \\
\hline \multicolumn{6}{|l|}{ Smoking during pregnancy $(1=$ yes, $2=$ no $)$} \\
\hline Internalising & $-1.18 *$ & 0.40 & -1.96 & -0.40 & 0.31 \\
\hline Multimorbid late onset & $-1.20 *$ & 0.43 & -2.04 & -0.36 & 0.30 \\
\hline Normative maturing & $-0.87 *$ & 0.30 & -1.47 & -0.28 & 0.42 \\
\hline Multimorbid remitting & $-0.83 *$ & 0.27 & -1.36 & -0.30 & 0.44 \\
\hline Multimorbid with remitting externalising & $-1.19 *$ & 0.31 & -1.80 & -0.58 & 0.30 \\
\hline \multicolumn{6}{|l|}{ Maternal post-natal depression $(1=$ yes, $2=$ no $)$} \\
\hline Internalising & $-0.97 *$ & 0.34 & -1.64 & -0.29 & 0.38 \\
\hline Multimorbid late onset & -0.64 & 0.48 & -1.57 & 0.29 & 0.53 \\
\hline Normative maturing & $-1.12 *$ & 0.46 & -2.01 & -0.22 & 0.33 \\
\hline Multimorbid remitting & $-0.88^{*}$ & 0.27 & -1.41 & -0.35 & 0.41 \\
\hline Multimorbid with remitting externalising & -0.49 & 0.55 & -1.56 & 0.58 & 0.62 \\
\hline \multicolumn{6}{|l|}{ Sensation-seeking (age 7) } \\
\hline Internalising & -0.05 & 0.08 & -0.21 & 0.10 & 0.95 \\
\hline Multimorbid late onset & -0.05 & 0.12 & -0.29 & 0.19 & 0.96 \\
\hline Normative maturing & 0.01 & 0.06 & -0.11 & 0.13 & 1.01 \\
\hline Multimorbid remitting & -0.09 & 0.08 & -0.24 & 0.06 & 0.92 \\
\hline Multimorbid with remitting externalising & 0.00 & 0.10 & -0.20 & 0.19 & 1.00 \\
\hline \multicolumn{6}{|l|}{ Bullying victimisation (age 11) } \\
\hline Internalising & 0.06 & 0.04 & -0.03 & 0.14 & 1.06 \\
\hline Multimorbid late onset & $0.14 *$ & 0.03 & 0.09 & 0.20 & 1.15 \\
\hline Normative maturing & $0.09 *$ & 0.03 & 0.04 & 0.15 & 1.10 \\
\hline Multimorbid remitting & $0.14 *$ & 0.03 & 0.08 & 0.20 & 1.15 \\
\hline Multimorbid with remitting externalising & $0.13 *$ & 0.04 & 0.06 & 0.20 & 1.14 \\
\hline \multicolumn{6}{|l|}{ Academic achievement (age 11) } \\
\hline Internalising & $-0.39 *$ & 0.09 & -0.56 & -0.23 & 0.67 \\
\hline Multimorbid late onset & $-0.41^{*}$ & 0.05 & -0.50 & -0.32 & 0.66 \\
\hline Normative maturing & $-0.38^{*}$ & 0.09 & -0.56 & -0.20 & 0.68 \\
\hline Multimorbid remitting & $-0.47 *$ & 0.06 & -0.59 & -0.35 & 0.62 \\
\hline Multimorbid with remitting externalising & $-0.52 *$ & 0.09 & -0.70 & -0.34 & 0.60 \\
\hline
\end{tabular}

* significant at $p<.05$ for our group comparisons limited the number of groups that could be extracted in our GBTM. Limiting our number of groups to six gave us a smallest group size that likely meant that our analyses were under-powered to detect very small effects involving this group. Such small effects were, however, judged to be unlikely to be of a magnitude where they would be clinically important. Second, we used only teacher reports of symptoms to construct our mental health trajectories. This allowed us to avoid common rater bias [38] when assessing the relations between trajectories and covariates (which were based on parent reports and youth self-reports); however, previous evidence suggests young people show different symptoms in different contexts and/or in interaction with different informants [12, 27]. This makes it important to assess the generalisability of conclusions across reports from different informants. Teacher-reports may also have some disadvantages compared with reports from other informants, especially in adolescence where their interactions with the young person may be limited. Further, though this issue is not limited to teacher-reports, teacher-reports have previously been shown to be biased by factors as halo effects [1] Third, it was not possible to tell why improvements and deteriorations in symptoms occurred. We did not have sufficient information, for example, to evaluate the role of exposure to 
diagnosis and clinical interventions on symptom improvements among those showing symptom decreases over development. Group-based trajectory modelling in cohorts with more detailed information on intervention exposure and timing would help clarify the extent to which improvements are spontaneous versus attributable to treatments for mental health symptoms. Fourth, in common with all modelling approaches, it is important to consider what can and cannot be inferred from applications of the model (see [6, 31] for discussions). In particular, while GBTM seeks to provide a useful and potentially clinically meaningful summary of heterogeneous trajectories, the groups that emerge should not be taken to literally exist. Under different modelling decisions (e.g., inclusion of within-group random effects, inclusion of additional or fewer higher-order growth parameters) different groups from those that emerged in the current analysis may have been indicated and these modelling decisions, as well as the interpretation of the groups are inevitably subjective.

\section{Conclusions}

When considering ADHD, internalising and externalising symptoms across childhood and adolescence, heterogeneity in individual trajectories can be usefully summarised in terms of a small number of developmental subtypes. A model with six developmental subtypes was considered optimal in this study. Subtypes included two normative subtypes ('unaffected' and 'normative maturing') and four subtypes that showed elevated mental health symptoms, three of which showed evidence of developmentally coupled symptom elevations in all three domains, and one of which was characterised by a late onset of symptoms. Covariate analyses suggested that males and bully victims tend to have complex mental health profiles; academic achievement and smoking during pregnancy have generalised associations with mental health irrespective of trajectory or combination of symptoms; and maternal post-natal depression is primarily related to symptoms that are already in evidence by childhood.

Funding Funding from the Jacobs Foundation and Swiss National Science Foundation are gratefully acknowledged.

Data availability Data and other relevant materials can be made available by request to the first author.

Code availability Code can be made available by request to the first author.

\section{Compliance with ethical standards}

Conflict of interest The authors have no conflicts of interest to declare.
Ethical approval The current research received ethical approval from the Ethics Committee of the Faculty of Arts and Social Sciences of the University of Zurich.

Open Access This article is licensed under a Creative Commons Attribution 4.0 International License, which permits use, sharing, adaptation, distribution and reproduction in any medium or format, as long as you give appropriate credit to the original author(s) and the source, provide a link to the Creative Commons licence, and indicate if changes were made. The images or other third party material in this article are included in the article's Creative Commons licence, unless indicated otherwise in a credit line to the material. If material is not included in the article's Creative Commons licence and your intended use is not permitted by statutory regulation or exceeds the permitted use, you will need to obtain permission directly from the copyright holder. To view a copy of this licence, visit http://creativecommons.org/licenses/by/4.0/.

\section{References}

1. Abikoff H, Courtney M, Pelham WE, Koplewicz HS (1993) Teachers' ratings of disruptive behaviors: The influence of halo effects. J Abnorm Child Psychol 21(5):519-533

2. Alsaker F, Gutzwiller-Helfenfinger E (2010) Social behavior and peer relationships of victims, bully-victims, and bullies in kindergarten. In: Jimerson Shane R, Swearer Susan M, Espelage Dorothy L (eds) Handbook of School Bullying. An International Perspective. Lawrence Erlbaum, Mahwah, pp 87-99

3. Angold A, Costello EJ, Erkanli A (1999) Comorbidity. J Child Psychol Psychiatry Allied Discip 40:57-87

4. Arseneault L (2018) Annual research review: the persistent and pervasive impact of being bullied in childhood and adolescence: implications for policy and practice. J Child Psychol Psychiatry 59:405-421

5. American Psychiatric Association (2013) Diagnostic and statistical manual of mental disorders (DSM-5®). American Psychiatric Pub, Washington, D. C

6. Bauer DJ (2007) Observations on the use of growth mixture models in psychological research. Multivar Behav Res 42(4):757-786

7. Beauchaine TP, Cicchetti D (2016) A new generation of comorbidity research in the era of neuroscience and research domain criteria. Dev Psychopathol 28:891-894

8. Beauchaine TP, McNulty T (2013) Comorbidities and continuities as ontogenic processes: toward a developmental spectrum model of externalizing psychopathology. Dev Psychopathol 25:1505-1528

9. van Buuren S, Groothuis-Oudshoorn K (2010) Mice: Multivariate imputation by chained equations in R. Journal of Statistical Software 45:1-68

10. Caspi A, Houts RM, Belsky DW, Goldman-Mellor SJ, Harrington H, Israel S, Meier MH, Ramrakha S, Shalev I, Poulton R (2014) The $\mathrm{p}$ factor: One general psychopathology factor in the structure of psychiatric disorders? Clin Psychol Sci 2(2):119-137

11. Cook CR, Williams KR, Guerra NG, Kim TE, Sadek S (2010) Predictors of bullying and victimization in childhood and adolescence: A meta-analytic investigation. Sch Psychol Q 25(2):65

12. De Los Reyes A (2013) Strategic objectives for improving understanding of informant discrepancies in developmental psychopathology research. Dev Psychopathol 25(3):669-682

13. Eisner NL, Murray AL, Eisner M, Ribeaud D (2018) A practical guide to the analysis of non-response and attrition in longitudinal research using a real data example. Int J Behav Develop. https:// doi.org/10.1177/0165025418797004 
14. Fanti KA, Henrich CC (2010) Trajectories of pure and cooccurring internalizing and externalizing problems from age 2 to age 12: findings from the National Institute of Child Health and Human Development Study of Early Child Care. Dev Psychol 46:1159

15. Ganzeboom HB, De Graaf PM, Treiman DJ (1992) A standard international socio-economic index of occupational status. Soc Sci Res 21(1):1-56

16. Graziano PA, Reid A, Slavec J, Paneto A, McNamara JP, Geffken GR (2015) ADHD symptomatology and risky health, driving, and financial behaviors in college: the mediating role of sensation seeking and effortful control. J AttenDisord 19:179-190

17. Jarrett MA, Ollendick TH (2008) A conceptual review of the comorbidity of attention-deficit/hyperactivity disorder and anxiety: Implications for future research and practice. Clin Psychol Rev 28:1266-1280

18. Lahey BB, Pelham WE, Loney J, Lee SS, Willcutt E (2005) Instability of the DSM-IV subtypes of ADHD from preschool through elementary school. Arch Gen Psychiatry 62(8):896-902

19. Mann FD, Engelhardt L, Briley DA, Grotzinger AD, Patterson MW, Tackett JL, Slutske W (2017) Sensation seeking and impulsive traits as personality endophenotypes for antisocial behavior: evidence from two independent samples. Personal Individ Differ 105:30-39

20. Martel MM (2013) Sexual selection and sex differences in the prevalence of childhood externalizing and adolescent internalizing disorders. Psychol Bull 139(6):1221

21. McDonald RP (1999) Test theory: a unified treatment. Psychology press, Hove

22. McLeod JD, Uemura R, Rohrman S (2012) Adolescent mental health, behavior problems, and academic achievement. J Health SocBehav 53:482-497

23. Moffitt TE (1993) Adolescence-limited and life-course-persistent antisocial behavior: a developmental taxonomy, 100 psychol. Rev 674:675

24. Murray AL, Eisner M, Ribeaud D (2016) The development of the general factor of psychopathology ' $p$ factor'through childhood and adolescence. Journal of Abnorm Child Psychol 44(8):1573-1586

25. Murray A, Eisner M, Ribeaud D, Kaiser D, McKenzie K, Murray G (2019) Validation of a brief self-report measure of adolescent bullying perpetration and victimisation: The Zurich Brief Bullying Scales (ZBBS). Assessment. 1-13. Online First

26. Murray AL, Booth T, Auyeung B, Eisner M, Ribeaud D, Obsuth I (2018) Outcomes of ADHD symptoms in late adolescence: are developmental subtypes important? J AttenDisord. https://doi. org/10.1177/1087054718790588

27. Murray AL, Booth T, Ribeaud D, Eisner M (2018) Disagreeing about development: an analysis of parent-teacher agreement in ADHD symptom trajectories across the elementary school years. Int J Methods Psychiatr Res 27:1723

28. Murray AL, Eisner M, Obsuth I, Ribeaud D (2017) Identifying early markers of "Late Onset" attention deficit and hyperactivity/impulsivity symptoms. J AttentDisord. https://doi. org/10.1177/1087054717705202

29. Murray AL, Eisner M, Ribeaud D (2017) Can the Social Behavior Questionnaire help meet the need for dimensional, transdiagnostic measures of childhood and adolescent psychopathology? Eur J Psychol Assess 35:674-679

30. Nagin DS, Nagin D (2005) Group-based modeling of development. Harvard University Press
31. Nagin DS, Odgers CL (2010) Group-based trajectory modeling in clinical research. Annual Review of Clinical Psychology 6:109-138

32. Nagin DS, Jones BL, Passos VL, Tremblay RE (2018) Groupbased multi-trajectory modeling. Stat Methods Med Res 27:2015-2023

33. Newman DL, Moffitt TE, Caspi A, Silva PA (1998) Comorbid mental disorders: Implications for treatment and sample selection. J Abnorm Psychol 107(2):305

34. Nivard MG, Lubke GH, Dolan CV, Evans DM, Pourcain BS, Munafò MR, Middeldorp CM (2017) Joint developmental trajectories of internalizing and externalizing disorders between childhood and adolescence. Dev Psychopathol 29:919-928

35. O'hara MW, McCabe JE (2013) Postpartum depression: current status and future directions. Ann Rev Clin Psychol 9:379-407

36. Parkes A, Sweeting H, Wight D (2016) Early childhood precursors and school age correlates of different internalising problem trajectories among young children. J Abnorm Child Psychol 44:1333-1346

37. Patalay P, Moulton V, Goodman A, Ploubidis GB (2017) Crossdomain symptom development typologies and their antecedents: results from the UK millennium cohort study. J Am Acad Child Adolesc Psychiatry 56:765-776

38. Podsakoff PM, MacKenzie SB, Lee J-Y, Podsakoff NP (2003) Common method biases in behavioral research: A critical review of the literature and recommended remedies. Journal of Applied Psychology 88(5):879

39. Polanczyk G, De Lima MS, Horta BL, Biederman J, Rohde LA (2007) The worldwide prevalence of ADHD: a systematic review and metaregression analysis. Am J Psychiatry 164:942-948

40. Reiss F (2013) Socioeconomic inequalities and mental health problems in children and adolescents: a systematic review. Soc Sci Med 90:24-31

41. Roeder K, Lynch KG, Nagin DS (1999) Modeling uncertainty in latent class membership: A case study in criminology. J Amer Stat Ass 94(447):766-776

42. Rubin DB (1976) Inference and missing data. Biometrika 63(3):581-592

43. Rubin DB (2004) Multiple imputation for nonresponse in surveys, vol 81. John Wiley \& Sons

44. Sutin AR, Flynn HA, Terracciano A (2017) Maternal cigarette smoking during pregnancy and the trajectory of externalizing and internalizing symptoms across childhood: similarities and differences across parent, teacher, and self reports. J Psychiatr Res 91:145-148

45. Tremblay RE, Loeber R, Gagnon C, Charlebois P, Larivee S, LeBlanc M (1991) Disruptive boys with stable and unstable high fighting behavior patterns during junior elementary school. J Abnorm Child Psychol 19(3):285-300

46. van Lier PA, Vitaro F, Barker ED, Brendgen M, Tremblay RE, Boivin M (2012) Peer victimization, poor academic achievement, and the link between childhood externalizing and internalizing problems. Child Dev 83:1775-1788

47. Wiggins JL, Mitchell C, Hyde LW, Monk CS (2015) Identifying early pathways of risk and resilience: the codevelopment of internalizing and externalizing symptoms and the role of harsh parenting. Dev Psychopathol 27:1295-1312 